\title{
E1 problema de las relaciones Iglesia-Estado en México
}

Las relaciones Iglesia-Estado y la actividad política de la Iglesia Católica se han convertido cada vez más en tema de discusión y polémica pública en México. La reanudación del debate Igles:a-Estado luego de cuarenta años de relativa tranquilidad y de una estabilidad. inquebrantable, sugiere que los cimientos de este consenso, aparentemente tranquilo, puede estar trizándose o, al menos debilitándose. Los líderes religiosos se están pronunciando públicamente sobre temas sociales, económicos y políticos y sus opiniones tienen más peso que en el pasado. Hasta hace poco tiempo las discrepancias se comentaban en una privacidad burocrática, tras una paradojica pero estable fachada.

Este retorno al debate Iglesia-Estado refleja tanto una continuidad como un cambio en el proceso polf́tico. El debate se ha visto estimulado por la extraordinaria confianza en sí mismos que han desarrollado los líderes religiosos, como también influenciados por las dificultades que enfrentan las autoridades civiles ante los desaf́ós económicos y sociales más ser ics, desde la Revolución. Los resultados de un debate tan fundamental como éste, dependerán de la tradicional estabilidad del proceso mexicano, de la flexibilidad del sistema de negociación política y del grado de compromiso de los líderes religiosos con el proceso político ${ }^{1}$.

Los líderes de la Iglesia ahora están desafiando el status quo al que ellos han estado esencialmente ligados durante los últimos cuarenta años. En este contexto la responsabilidad pública reguiere que tal desafio también incluya la autocrítica. La reanudación de las negociaciones públicas sobre la relación Iglesia-Estado, no necèsariamente refleja la debilidad e indefensión del pasado, como tampoco el anticlericalismo y el temor al humanismo secular que marcó las relaciones Iglesia-Estado en el pasado. Sin embargo, los líderes

Para un debate útil sobre los desafios que enfrentan las tradicionales negociaciones políticas en México, ver: Susan Kaufman Purcell \& John F. H. Purccll, "El Estado y la Sociedad en México: una politica estable debe institucionalizar-

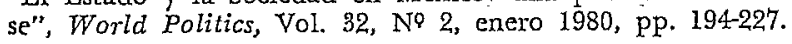


religiosos no están movidos por un consenso religioso ni por objetivos determinados. Los conflictos surgen inesperadamente y reciben respuestas superficiales. Existe escasa comunicación y con:enso entre los mismos obispos. Mientras algunos obispos favorecen un acercamiento de tipo personal, informal e indirecto en las negociaciones, otros están por un proceso formal, público y abierto.

EI contexto formal en que se desenvuelven las relaciones IglesiaEstado en México, es diferente al de otros países en Latinoamérica. Además de la presión ejercida por antiguos conflictos, la Iglesia está fuertemente condicionada por la religiosidad popular. El proceso de restauración y renovación de prácticas e instituciones eclesiásticas ha sido, a la vez, estimulado y restringido por las diversas y distintas formas de religiosidad popular. Existe una gran brecha entre la Iglesia oficial de los sacramentos y autoridad jerárqu ca y el mundo de los rituales populares. Esta brecha limita a los líderes y restringe las reformas. Los debates ideológicos, las transformaciones institucionales de la Iglesia y las políticas sociales y educacionales, no ban afectado directamente a la mayorfa de los miembros de la Iglesia. Las renovaciones y reformas religiosas son acatadas principalmente en las áreas urbanas y entre los miembros más observantes y ligados a la Iglesia.

Algunos líderes eclesiásticos han intentado llevar estas reformas a las áreas rurales, enfrentándose a sus colegas y a las autoridades civiles. La Iglesia Mexicana se ha visto influenciada por dos hechos importantes: 1. La resolución de los conflictos Iglesia-Estado en los años 20 y 30 , que fijó el camino para un largo período de crecimiento institucional para la Iglesia; y 2. la renovación a nivel mundial del Catolicismo y de las religiones, en general, promovida por Vaticano II y las Conferencias de Obispos Latinoamericanos en Medellín en 1968 y en Puebla en 1979. En México estos dos hechos se ven más claros a la luz de los sucesos de Tlatelolco en 1968, donde centenas de estudiantes fueron muertos por el Gobiemo, con el consiguiente debilitamiento de la autoridad presidencial. La singular tradición religiosa de México y el contexto de las relaciones IglesiaEstado ayudaron en la transformación de la Iglesia. Los cambios fueron muy irregulares en la Iglesia Mexicana. No fue poco común, en el pasado, escuchar a líderes religiosos decir que las reformas de Vaticano Ir, Medellín y Puebla no eran aplicables a México.

Fue inevitable que las relaciones Iglesia-Estado se sometieran a escrutinio público, sin embargo las tensiones ya existentes se mantuvieron. Surgen dificultades en el camino. Entre las autoridades civiles como religiosas existe un profundo rencor por los acontecimientos del pasado. Existen muchos desacuerdos políticos entre los mexicanos acerca del futuro de la Iglesia. El problema se intensif:ca por una crisis de autoridad dentro de la Iglesia, una crisis que ha 
obligado a intervenir al Vaticano. A continuación examinaremos el marco en que se desarrollaron las diversas controversias religiosas y sus causas.

\section{La desintegración del consenso religioso}

La Iglesia Católica Mexicana ha sido una de las menos conflictivas y más cautelosa de Latinoamérica desde los comienzos de la década de los 40. Los líderes de la Iglesia ejercían una política bastante discreta y preferían más las negociaciones privadas que la confrontación pública, respetando cuidadosamente las reglas del juego polftico. La cautela de los líderes de la Ig esia, fue el resultado de los tradicionales conflictos como también del contexto en que se desen. vuelven las relaciones del Estado con la sociedad en general, en México. La discreción de los líderes religiosos en México contrastaba fuertemente con la presión política explícita que ejercían las iglesias de otros países latinoamericanos y con la participación activa de las iglesias de los Estados Unidos en controversias públicas tales como el aborto, la pobreza y las armas nucleares.

Durante los años 80, los líderes religiosos mexicanos han abandonado esta tradicional reserva y han iniciado actividades políticas, cambios que representan un desafío a los convenios pasados y un intento por reimplantar el poder de la Iglesia en la sociedad. Como resultado, el consenso religioso del pasado ha comenzado a desintegrarse 2 . Esta dedicación renovada de la Iglesia por los problemas públicos surge de su propia tradición social. Los mexicanos católicos se inspiraron en las Enclíclicas Sociales del Papa León xni. Estas primeras enseñanzas sociales fueron aplicadas en México a través del Secretariado Social de México (SSM), establecido por los obispos en la década de los años 20. El Secretariado Social de México (SSM) oficialmente representó la opinión de los obispos hasta $1970^{3}$.

En 1982, el Comité Ejecutivo de la Conferencia Episcopal publicó una Declaración firmada por el Cardenal Corripio Ahumada, er ese entonces Presidente de la Conferencia Episcopal Mexicana (CEM), decafiando las restricciones lega!es existentes sobre la Iglesia y el

${ }^{2}$ Dennis M. Hanratty, "El rol politico de la Iglesia Católica Mexicana: Temas Contemporáneos", Thought, junio 1984, pp. 164-182.

"Jorge Adame Goddard, El pensamiento politico y social de los católicos mexicanos (México: UNAM, 1981), pp. 199-225.

Eduard Larry Mayer, La politica social de la Iglesia Católica en México a partir del Concilio Vaticano II (UNAM. Tesis profesional, 1977), pp. 274-279 .

Documentos colectivos de los Obispos MLexicanos (México: Paulinas, 1977). Ver: "Cartas sobre el Desarrollo e Integración de Nuestra Patria", (26 de marzo de 1968). Este documento va contra el apoyo de los Obispos que respaldan al Gobierno en la represión estudiantil. 
clero. La Declaración advertía que los obispos, de ahí en adelante, buscarian un diálogo abierto y responsable con las autoridades civices en un esfuerzo por cambiar directa o indirectamente el status jurídico de la Iglesia ${ }^{4}$.

Este nuevo zctivismo se manifestó en una muestra amplia y representativa de la jerarquía. Entre Ios obispos activistas se encuentra el Presidente de Ia Conferencia Episcopal Mexicana (CEM) desde 1982, Sergio Obeso Rivera (Arzobispo de Xalapa), a Ernesto Corripio Ahumada (Cardenal Arzobispo de Ciudad de Méxjco), al Arzobispo Ouintero Arceo de Hermosillo, al Arzobispo Carrasco Briseño, de Oaxaca y a los Obispos Samuel Ruiz (San Crictóbal de las Casas), Arturo Lona (Tehuantepec), Manuel Talamás (Ciudad Yuárez) y Sergio Méndex Arceo (retirado de Cuernavaca). Estos obispos son Ifderes en dos campos que se relacionan entre sí: el de los valores en la sociedad y la polftica y en el de las relac'ones Iglesia-Estado. Algunos obispos se han pronunciado abiertamente en materias tales como reforma institucional y autoridad y liderazgo de los laicos, como también sobre elecciones, partidos políticos, sindicatos, co-

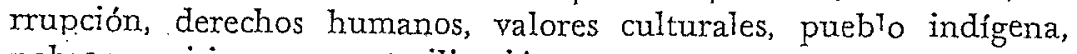
pobreza, prisioneros y esterilización.

El primer obispo que abiertamente desafió el muro de separación nolítica fue Seroio Méndez Arceo, anteriormente perteneciente a Ja Diócesis de Cuernavaca en el Estado de Morelos (1952-1983). Este peaueño estado. al sur de Ciudad de México. fue la cuna de Emiliano Zapata. Méndez Arceo inició cambios litúrgicos en la década de Jos 50 , a los cuales les siguieron otras innovaciones en muchas áreas de la polf́tica de la Inlesia en la década de los 60 y 70 . Fíl se dio $a$ conocer por sus declaraciones francas $\mathrm{v}$ progresistas $\mathrm{v}$ por sus programas de reformas religiosas en apoyo de los derechos poIfticos y sociales de los trabajadores y de los pobres en México y Latinoamérica. Asombró a los obispos al dialogar con marxistas, apoyando huelgas, defendiendo a los estudiantes (especialmente durante las protestas de 1968 y 1971), excomulgando a los torturadores e increpando a políticos y religiosos reaccionarios. En su Diócesis, él compartió el ejercicio de su autoridad religiosa con el clero, monjas y líderes laicos, a través de uno de los primeros concilios diocesanos en México. Sus sermones dominicales consistían en una imaginativa mezcla de situaciones locales, nacionales e internacionales interpretadas a la luz de los Evangelios, de la tradición social de la Iglesia y fusionada a la tradición humanística del Socialismo. Frecuentemente era citado en la prensa de Ciudad de México y atacado por

"Ver Proceso, "La Iglesia no puede quedar fuera del Derecho", el 17 de noviembre de 1982; también el 22 de noviembre de 1982. 
el ala derecha, acusándolo de ser un temible religioso revolucionario, "un obispo comunista"5.

A pesar de estar frecuentemente en oposición con el resto de los obispos, sin embargo Mons. Méndez Arceo fue un pionero por su forma de ingresar a la arena política y por sus comentarios sobre materias sociales.

El Cardenal Arzobispo de Ciudad de México y el Presidente de la Conferencia Episcopal Mexicana (CEMI), eran considerados moderados con respecto a su enfoque personal sobre el desafío que planteaba el status quo y las restricciones civiles del clero. Por ejemplo, el documento público más reciente bajo su jurisdicción define las prioridades de la Iglesia sin mencionar los temas constitucionales $y$ sólo indirectamente tocando cualquier tema político ${ }^{6}$.

Sin embargo, estos "moderados" han sido los más abiertos oponentes a las reformas religiosas dentro de la Iglesia. Otros obispos, especialmente de las diócesis del norte del país, han sido más discutidos por identificarse con las políticas del partido opositor conservador P.AN, partido que se atribuye la representación de las enseñanzas sociales de la Iglesia 7 .

Más aún, otro grupo de obispos ha adoptado una posición diferente y trabaja en las zonas más pobre y a lejadas de México. Ellos representan una antigua tradición de radicalismo social que tiene sus raíces desde los tiempos de la defensa de indígenas en los territorios de Nueva España, por parte de obispos y clero. Estos obispos rechazan un partidismo directo, pero abiertamente denuncian las injustas condiciones políticas y sociates de su región. Ellos nunca han apoyado ni condenado a determinados partidos por su ideología ${ }^{8}$.

La creciente actividad social y política de los obispos desató controversias en la prensa $y$ oposición del oficialismo del PRx, junto con periódicos llamados de los diputados en el Congreso para una intervención del Gobierno. S'n embargo, hasta ahora no ha habido una respuesta oficial por parte de los órganos ejecutivos, notoria omisión dadas las implicancias de tales temas en discusión. De hecho, los últimos dos iefes ejecutivos han apoyado en cierta forma a la autoridad de los líderes de la IgTesia por medio de gestos simbólicos. Estos Presidentes han sido Luis Echeverría (1970-1976) y Tosé López Portillo (1976-1982). Echeverría visitó el Vaticano en 1974,

"Gabriela Videla, Sergio Méndez Arceo, Un Señor Obispo (Cuernavaca: Correo del Sur, 1982). El eiemplo más notorio de juicio crftico a Méndez Arceo In constituye la Declaración pública hecha por sus compañeros obispos del Conseio Ejecutivo del cEM, marzo 9, 1978. Ver: Lauro López Beltrán, Diócesis y Obispos de Cuemavaca, 1975-1978 (México: junio 1978), pp. 286-287.

"Plan Orgánico de Trabajo Pastoral de la cEar, 1983-1985", (julio, 1983).

"Oscar González Gari, et al, "Batallas en el Reino de este Mundo", Nexos 24, junio 1984, p. 21.

sibid., p. 24. 
siendo el primer Presidente en hacerlo en este siglo, gesto que fue calificado por los jerarcas de la Iglesia como un significativo acercamiento. La Administración de López Portillo fomentó y facilitó la construcción de la nueva Basílica de Guadalupe en Giudad de México. El, personalmente, aunque no oficialmente, recibió al Papa en su res:dencia en 1979. El Presidente Miguel de la Madrid, jefe del Ejecutivo desde 1982, es gran amigo del Cardenal Corripio Ahumada.

La pasividad demostrada por los líderes de la Iglesia en el pasado puede parecer quizás más paradójica que la actividad política del presente: El poder destructivo de los antiguos conflictos trajo consigo un extenso periodo de tranquilidad. De esta tranquilidad surgió una nueva conciencia y estrategia religiosa. Aunque la mayoría de los mexicanos son católicos por cultura y prácticas populares, la Iglesia como institución no tiene un status legal. Este vacio constitucional se derivó de las claras metas y raíces del liberalismo secular a que se adhirieron los reformadores del siglo 19. La combatividad del liberalismo mexicano fue desafiada por una Iglesia agresiva que enfrentaba a un Estado y gobierno débiles. El anticlericalismo de los revolucionarios del siglo $\mathrm{xx}$ fue codificado en el Artículo 130 de la Constitución de $1917^{\mathrm{g}}$.

La ideologia oficial del PRI combina un anticlericalismo agresivo con una larga tradición de rituales populares que pueden ser rastreados desde los comienzos del nacionalismo mexicano ${ }^{10}$.

La esencia antirreligiosa del Estado actual se encuentra también profundamente enraizada en el pasado. Ningún hecho o período aislado del pasado puede explicar todo esto; en cierta forma está artificialmente sustentado en la sospecha de que los líderes eclesiásticos estarían prontos a apoderarse del Estado ante el menor signo de debilidad, restableciendo una destructiva hegemonía religiosa, si no una teocracia. Tales antagonismos están alimentados por ideologías y rituales públicos que continúan favoreciendo las políticas oficialistas. - La Constitución es vista por los líderes religiosos como una amenaza latente. No es de sorprenderse, entonces, que ahora busquen medios para reducir tal amenaza.

Las sanciones constitucionales contra la religión y el clero parecen también haber restringido las investigaciones académicas. Hasta hace poco tiempo, escaso esfuerzo se desarrollaba para explicar objetivamente la institución de la Iglesia. Hoy en día los académicos observan más objetiva y cuidadosamente el rol político y social.

'Jorge Carpizo, La Constitución Mexicana de 1917 (México: UNaM, 1969), pp. 263-265.

10David Brading, Los origenes del nacionalismo mexicano (México: Era, 1973), Pp. 23-28. Ver también Jacques Lafaye, Quetzalcoatl y Guadalupe (Chicago: The University of Chicago Press, 1976), pp. 274-298. 
Claude Pomerleau, CSC. / El problema de las relaciones Iglesia-Estado...

de la Iglesia. Los tres perfodos de la evolución de la Iglesia que más interesan a los estudiosos son los conflictos post-revolucionarios y la Rebelión de Cristero, el restablecimiento de la tranquilidad entre los años 40 al 60 , y la Iglesia contemporánea influenciada por Vaticano II y las reformas en otras iglesias latinoamericanas ${ }^{11}$.

El pasado religioso de México tiene una gran importancia. La situación Iglesia-Estado ha producido una Iglesia indígena fuerte. Para comprender las presiones del presente, debemos volvernos a la estructura del pasado.

\section{Un marco para la estabilidad: la presencia del pasado}

Dos hechos han sido los que han afectado más profundamente el desarrollo y la renovacjón de la Iglesia luego de la Revolución de 1910. El primer hecho fue Ja tregua establecida entre el Estado mexicano y la Iglesia. El segundo, la renovación mundial experimentada por la Iglesia Católica Romana en relación a su organización, como también a sus relaciones con el Estado y la sociedad. El primer hecho permitió a la Iglesia recuperar gran parte del terreno moral y religioso perdido durante las desgastadoras luchas civiles, especialmente con el Estado. El segundo acontecimiento forzó a una reevaluación de la estrategia de la Iglesia en lo social y religioso, como asimismo a la auto.comprensión religiosa de los miembros laicos, clero y jerarquía.

La Revolución de 1910 debilitó parte de los antiguos anremios económicos $Y$ políticos impuestos a la Ig'esia por los regímenes liberal y positivista del siglo anterior. Lo: revolucionarios esveraban estimular el desarrollo económico y apadrinar los cambios políticos y sociales, sin perder los beneficios ideológicos del pasado. Los líderes de la Iglesia, por su parte esperaban recuperar parte del terreno perdido como resultado de los conflictos y destructivas alianzas sostenidas en el pasado. Ellos formularon nuevos planes para apoyar a los sindicatos, a las organizaciones campesinas y despertar el nacionalismo religioso. Los revolucionarios de este siglo no estaban dispuestos a comprometerse con los líderes de la Iglesia, optando por una fórmula constitucional que llevara implícito considerables trabas a la Iglesia y dejar a criterio del nuevo Estado el aplicarlas convenientemente y promulgar las leyes apropiadas. Estas restriccio-

\footnotetext{
"Para el perfodo de Cristero ver: David C. Bailey, „Viva Cristo Rey! La Rebelión de Cristero y el conflicto Iglesia-Estado en México (Austin: The Universily of Texas Press, 1974). Para el periodo entre 1940 al 60, ver: Soledad Loaeza, "La restauración de la Iglesia en México, 1940-1960", en Martín de la Rosa y Carlos Reilly (eds.), Religión y Politica en México (México: siglo xxI. Por aparecer). Y para el perfodo contemporáneo ver Patricia Arias et al., Radiografia de la Iglesia en México (México: UNAM, 1981).
} 
nes constitucionales no fueron aplicadas sino hasta la década del 20, con el liderazgo de los presidentes anticlericales ${ }^{12}$.

El anticlericalismo del Presidente Calles, de hecho produjo un violento alzamiento regional conocido como la Rebelión de Gristero (1926-1929), la cual perduró en forma latente hasta los años 30, incluso después que un tratado formal hubiera puesto fin a las hostilidades armadas, El fin de las hostilidades no eliminó las causas que originaron la Rebelión, una rebelión con profundas raíces de tipo cultural y religioso, como también con orígenes económicos y politicos ${ }^{13}$.

Los conflictos armados se sucedieron, en primer lugar, porque los católicos sentían que el Estado no les dejaba mayores alternativas para negociar la sobrevivencia de la Iglesia ni el ejercicio libre de la religión. El Estado fue incapaz de derrotar a los rebeldes religiosos y los Cristeros tuvieron escasa relevancia en las políticas del Gobierno. Estas políticas fracasaron porque los líderes civiles fueron incapaces de distinguir entre los intereses religiosos, económicos, políticos y nacionales. La Iglesia también fracasó porque sus líderes fueron incapaces de universalizar sus objetivos religiosos y convertir las lealtades institucionales en un organizado apoyo popular. Cuando los obispos fueron, finalmente forzados a retirar su apoyo de la Liga Nacional para la Defensa de la Religión, ellos trataron de disculparse negando que hubieran incitado a la rebelión armada. Además, ellos continuaron reafirmando que los ciudadanos tenían derecho a la autodefensa en circunstancias determinadas, incluyen do la libertad religiosa, en última instancia ${ }^{14}$.

Los conflictos entre la Iglesia y el Estado no finalizaron hasta 1938 , una vez que tanto las autoridades civiles como religiosas concluyeran que más se obtenía negociando que a través de conflictos provocados por ideólogos violentos. Los líderes eclesiásticos estaban divididos en cuanto a las estrategias políticas a seguir, pero el nuevo Arzobispo de Ciudad de México en 1938, estaba decidido a seguir el camino de las negociaciones pacíficas, de acuerdo con las polítiças de Roma.

EI Presidente Cárdenas, por otro lado, resueltamente concluyó que su reforma social arrjesgaba perderse si no se daba una solución al problema religioso ${ }^{15}$. El ingenió un açuerdo privado e informal

LaJean A. Meyer. La Rebelion de Cristero (Cambridge: Cambridge University Press, 1976). pp. 48-66.

Ver también al mismo autor en Estado y Sociedad con Calles: Historia de la Revolución Mexicana, Vol. II (México: Il Colegio de México, 1977), pp. 210218.

${ }^{23}$ Jean A. Meyer, La Rebelión de Cristero, op. cit., pp. 187-188.

1s Gunther Lewy, Religión y Revolución (N. Y.: Oxford University Press, 1974), p. 402.

${ }^{15}$ Albert L. Michaels, "La modificación del nacionalismo anticlerical de la 
compatible con sus otros compromisos, entre los sectores rural y urbano, y entre modernismo y tradicionalismo. Pudo resolver la larga diferencia existente entre los valores comunitarios del campesinado (incluidos planteamientos de tipo religioso) y los valores de empresarios progresistas basados en el individualismo y capitalismo liberal. El compromiso religioso fue el gancho para asegurar sus programas sociales. Los valores religiosos y temporales estaban dirigidos y subordinados a un estado unipartidista, bajo la autoridad politica absoluta del Presidente ${ }^{10}$.

El compromiso Iglesia-Estado fue públicamente ratificado por la Declaración del Presidente Manuel Avila Camacho en 1940: "Yo soy un católico", lo que fue publicado por la prensa como "Yo soy un creyente". La Iglesia pronto comenzó a recuperarse de los devastadores conflictos y restricciones sufridas en los últimos veinte años. Como resultado de estos anteriores conflictos, el número de sacerdotes había descendido a menos de 3.000 de un total de 7.000 a comienzos del siglo 19. Los templos habían sido descuidados o abandonados, y las escuelas y seminarios cerrados. Sólo algunos obispos habian mantenido seminarios clandestinos, pero la mayor parte de los candidatos al sacerdocio hacían sus estudios en los Estados Unidos o en el Seminario Nacional de Roma. Las órdenes religiosas habían sido expulsadas y a aquellos que permanecieron se les prohibió reclutar y practicar apostolados tradicionales.

Con posterioridad a 1940, sobrevino un asombroso y comprensible mejoramiento de la moral entre los miembros y líderes de la Iglesia. Se reabrieron las escuelas, se restablecieron los seminarios, se crearon nuevas diócesis. Los miembros exiliados de las órdenes religiosas pudieron retornar a México. Más del $95 \%$ de los 20 millones de mexicanos en 1940 eran católicos. Las comunidades indígenas hacía tiempo habian sido dejadas de lado, acentuando su aislamiento geográfico y cultural. EI líder religioso más influyente durante este período de restauración, fue Luis María Martínez, Arzobispo de Ciudad de México desde 1937 a 1956. Fue uno de los prelados más influyentes y respetado del siglo y gran amigo personal del Presidente Avila Camacho y más tarde del Presidente Miguel Alemán Valdés (1946-1952) y del Presidente Adolfo Ruiz Cortínez $(1952-1958)^{17}$.

El enfoque ideológico de la doctrina de la Iglesia en este período fue la cruzada contra el comunismo interno. Esta cruzada se

Revolución Mexicana por el General Lúzaio Cúrdenas", The Americas, Vol. 26, No 1, julio 1969, pp. 35-53.

10Fred Pike, América Hispana (N. Y.: Norton 1973), pp. 43-56.

rijosé Gutiérrez Casillas, SJ, Historia de la Iglesia en México (México: Porrua, 1974), p. 455. 
convirtió en la actividad central tanto de las organizaciones existentes como de las nuevas organizaciones de la Iglesia. La creciente importancia de la Guerra Fría para México después de 1947, hizo que el Gobierno convirtiera la lucha anticomunista en el objetivo central de su política externa. La Iglesia apoyó este objetivo en el ámbito doméstico. La euforia católica estaba abierta y explícitamente a favor de esta política gubernamental. El PAN había sido fundado en 1938 de acuerdo a los lineamientos de la Democracia Gristiana europea. Originariamente su objetivo había sido constituir:e en alternativa entre el Fascismo y el Comunismo, y más tarde servir de amortiguador entre los desacreditados corporatistas de la derecha y el marxismo de la izquierda. El anticomunismo de Ja Europa conservadora estaba combinado con la doctrina social de la Iglesia.

Los presidentes mexicano: desde los años 40 al 60 fueron anticomunistas y muy admirados por la clase media católica profesional. La cruzada anticomunista de la Iglesia permitió crear una organización semejante a un inmenso paraguas bajo el cual cobijar a todos los grupos de la Iglesia. Esta organización se denominó Confederación de Organizaciones Nacionales (CON). La CON fue fundada por el Rev. Pedro Velásquez, uno de los pensadores sociales más progresistas del catolicismo mexicano. Su catolicismo social reflexivo atrajo a toda una generación de líderes laicos y proporcionó un contexto adecuado para la creación de tales instituciones como la Acción Gatólica Mexicana y el Movimiento Familiar Cristiano. Católicos prominentes del mundo de los negocios, de las profesiones liberales y del Gobiemo se enrolaron en esta Confederación, entre ellos Bernardo Pacheco, fundador de la Unión de Empresarios Católicos, Luis M. Farias, entonces Director de Investigaciones del Ministerio del Interior, y Jo:é Alvarez Icaza, Presidente del Movimiento Familiar Cristiano. Alvarez Icaza recuerda los años 50 como de intenso activismo social y disciplina organizacional. Los objetivos políticos, sociales y religiosos de la jerarquía eran transmitidos a las organizaciones laicas a través de la con. Era poco frecuente que se conocieran desacuerdos, por pequeños que fueran ${ }^{18}$.

El anticomunismo reforzó la cooperación Iglesia-Estado, pero también afianzó la unidad interna de la Iglesia. Mientras que la cooperación de la Iglesia con el Estado aparecía muy sincera, la mayoría de los líderes religiosos rechazaban el socialismo revolucionario, por cuanto no era partidario de la democracia y era anticlerical, además rechazaban al liberalismo, por cuanto había minado los valores nacionales y religiosos. En aquellos primeros y plácidos

${ }^{10}$ Francisco Ortiz Pinchetti, Entrevista con Alvarez Icaza, Proceso; No 80, 14 de abril 1980, pp. 10-18. 
días, Ia Doctrina Social de la Iglesia se ofrecía como balanza entre dos extremos peligrosos ${ }^{19}$.

La jerarquía esperaba el triunfo de un organizado movimiento laico en pro de un camb:o social pacífico a través de la educación moral y el nacionalismo religioso. La fuerza de este movimiento laico fue la Acción Católica (AC). La Acción Católica se estructuró -según su homónima francesa- en cuatro ramas especializadas incorporando a estudiantes y trabajadores de ambos sexos. Para la jerarquía, la Accóni Católica parecía ser el vehículo más adecuado para penetrar e influir en el mundo académico y laboral. Aún más, la Acción Gatólica era el instrumento ideal para unificar a los estudiantes en contra del modernismo secular y a los trabajadores contra la ideología comunista. La Acción Católica fue definida como una extensión de la autoridad de la jerarquía, una palanca religiosa para mover a la sociedad secular hacia valores más religiosos. La estructura organizativa de la Acción Católica era esencialmente jerárquica, a imagen de la Iglesia misma, con una escala de autoridad que iba desde la jerarquía del clero, hasta los miembros laicos, aquellos peones indispensables de los obispos. La Acción Católica introdujo a los laicos en las actividades de la Igtesia a través de un modelo o estructura de autoridad que, con el tiempo, fue cuestionado y rechazado por teólogos y obispos en Vaticano Ir. En todo caso, en la década del 50, los miembros de la Acción Católica se estimaban en medio millón ${ }^{20}$.

Con el creciente aumento de movimientos populares durante los años 60 , y con el impacto de la renovación religiosa que se introdujo en la Iglesia mexicana, el liderazgo de la Acción Católica se vio más involucrado en las protestas de tipo social y político. Como resultado, se asoció estrechamente a la Acción Gatólica con las protestas estudiantiles y obreras de 1968. A pesar de los documentos sociales bastante progresistas emitidos por los obispos en 1968, el Arzobispo de Ciudad de México restringió las actividades de. la Acción Católica y bloqueó toda actividad política de sus miembros. Los liferes estudiantiles cesaron de protestar. La negativa de los obispos de condenar al Gobierno por la represión de 1968, fue el principio del fin para la Acción Gatólica. Sus miembros dism nuyeron y la organización "paraguas" para centralizar el liderazgo finalmente colapsó. Aunque los obispos posteriormente han intentado revivir la Acción Católica y restablecer el control sobre las organizaciones laicas, no se ha encontrado la fórmula para repetir el éxito del pasado.

Dentro de la estructura activa de la Iglesia, se han creado nue-

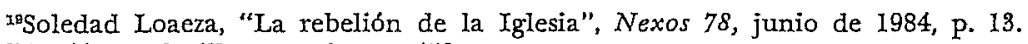

${ }^{\infty 0}$ Gutiérrez Casilla, op. cit., p. 453. 
vas organizaciones para la participación laica, sin perjuicio de renovar las antiguas. Algunas son asociaciones pias tradicionales sin objetivos políticos y con un limitado compromiso social; otras; en cambio, tienen objetivos sociales y políticos explícitos con un leve tinte de "inspiración cristiana". Algunas de estas nuevas organizaciones están orientadas especificamente hacia fines espirituales, tales como Encuentros Bíblicos, Carismáticos; Cursillos, Hijos de María y similares. Otras están involucradas en actividades de tipo social o profesional, bajo el control directo de los obispos locales, y ellas son la Gonferencia para el Estudio de la Iglesia Latinoamericana (CEFILA), Movimiento Internacional de Intelectuales Católicos (MIEC), Movimiento Familiar Cristiano (MFC) y Movimiento para un Mundo Mejor. A pesar de que algunas organizaciones ligadas a la Acción Católica permanecen, en general, la mayoría de las funciones que cumplía la Acción Católica han sido reemplazadas por comunidades de base de Ia Iglesia y por programas diocesanos. Quizás el desarrollo más significativo para la participación laica sea el número creciente de grupos inspirados por la doctrina de la Iglesia con fines educativos, organizacionales y de desarrollo, tanto en las áreas urbanas como rurales. Estos grupos a menudo surgen de las parroquias y constituyen un nexo muy significativo con las iglesias Iocales y las organizaciones seculares 21 .

Dentro de la Iglesia institucionalizada, el ámbito más difícil para organizar y manejar, es aquel relativo a los institutos religiosos para hombres y mujeres y el del clero diocesano. Ambos grupos constituyen el mayor número de profesionales organizados trabajando dentro de la administración de la Iglesia. En 1979 eran 37.873 religiosos de ambos sexos, relacionados en diversas formas de actividad eclesiástica, incluyendo 2.644 parroquias divididas en 73 diócesis con las correspondientes administraciones en cada nivel ${ }^{22}$.

Bajo las actuales prácticas pastorales, el sacerdote contimia siendo la figura religiosa dominante y la sola autoridad de la parroquia, en teoría. Sin embargo, debido al gran número de deserciones del sacerdocio (sobre 500 entre 1966 y 1983) y el insuficiente número de vocaciones sacerdotales, más y más parroquias dependen del manejo de los laicos, en muchos casos mujeres piadosas. La proporción de sacerdotes católicos en México es de uno por cada 6.648 católicos, lo cual es normal en Latinoamérica. Sin embargo, el clero está desigualmente distribuido y muchos son profesionales sin ministerio parroquial. Por ejemplo, mientras Guadalajara tiene un sacerdote por cada 2.500 católicos, la diócesis de Yucatán tiene

minael R. González R., SJ, Promoción Social (México: Estudios Sociales, 1978), pp. 145-158.

Annuarium Statisticum Eclesia 1979 (Roma). 
uno por cada $7.500^{23}$. En muchas parroquias la proporción de sacerdotes a fieles es tan alto como 1 a 50.000 , proporción que impide el desarrollo de cualquiera forma de comunidad o servicio eclesiástico, sin la participación y liderazgo de los laicos.

Un serio problema para la organización de la Iglesia ha sido el número decreciente de vocaciones sacerdotales, problema que se encara en toda Latinoamérica. Los seminarios en México muestran hoy su reciente reorganización, luego de generaciones de abandono. Muchos están pobremente equipados, con profesorado poco entrenado y con un escaso contacto con las instituciones intelectuales y culturales del país. Sintetizando una encuesta hecha a los seminarios y publicada en 1974, se encontró que muchos tenían bibliotecas insuficientes con pocas facilidades de tipo educativo, los profesores no estaban familiarizados con los últimos desarrollos teológicos como tampoco entrenados en el campo de las ciencias sociales. Los seminaristas no estaban preparados para trabajar con grupos, ni estaban al tanto de los problemas básicos de la familia y la sexualidad. La mayoría de los seminaristas entrevistados se quejaron de un ambiente de moral muy relativo y de falta de supervisión profesional ${ }^{24}$.

Los institutos religiosos, para hombres y mujeres, muchos de los cuales no son considerados parte del clero, están dejando sus tareas seculares especializadas para tomar tareas de asistencia al clero dentro de las parroquias. Ningún grupo dentro de Ja Iglesia Mexicana ha significado un impacto mayor para el cambio que la 'Compañía de Jesús (Jesuitas). En 1979 contaba con más de 400 miembros mexicanos trabajando para la Iglesia en parroquias, misiones, colegios, centros de investigación y medios de comunicación. Son asesores, administradores, líderes e intelectuales que participan en una amplia gama de inctituciones. Presentes en México desde el siglo 16. Ta gran influencia de los Jesuitas deriva de su participación directa en programas de renovación dentro de la Iglesia Mexicana, como también de sus diversas conexiones internacionales.

En 1971, los Jesuitas vendieron su más prestigioso colegio secundario, el "Instituto Patria" de Ciudad de México, invirtiendo el dinero en proyectos educativos y de desarrollo para los pobres. Su rol de educadores y reformadores radicales, les ha acarreado frecuentemente problemas con las autor:dades tanto civiles como eclesiásticas. Su posición de liderazgo profesional dentro de la Iglesia Mexicana, se ha visto desafiada, a partir de los años 70, por un instituto laico reaccionario español llamado Opus Dei. Aunque muchos obispos han intentado equilibrar al Opus Dei con la progresista

${ }^{3}$ Manuel R. González R., La Iglesia Mexicana en cifras (México: arAs, 1969), p. 101.

${ }^{21}$ Luis A. Núñez, SJ \& Félix Palencia, Seminarios y Seminaristas en Máxico (Chihuahua: Ed. Privada, 1974). 
Compañła de Jesús, los miembros del Opus Dei están menos dispuestos que los Jesuitas a integrar sus servicios con los programas diocesanos, especialmente cuando estos programas están en concordancia con el espíritu de renovación de Vaticano Ir.

Otra característica muy especial de la Iglesia Mexicana, es la relevanicia de la religión popular. Existen factores institucionales e ideológicos que influyen en la relación de la Iglesia oficial con la religión popular, incluida la brecha social que aún se da entre la cultura dominante y las culturas indígenas. El catolicismo ha tolerado fácilmente una gran variedad de prácticas religiosas populares. Debido a los muchos y muy diferentes rituales populares que han sobrevivido en México, los ritos populares y la religión sacramental han seguido caminos paralelos ${ }^{25}$.

El inmenso impacto de estas prácticas populares ha compelido a los líderes de la Iglesia a examinar su significación como un medio valioso para la renovación de las prácticas religiosas. El resurgimiento de la religión popular se ve ahora como un suplemento a las inadecuaciones de la Iglesia institucional. En el pasado, los líderes de la Iglesia habían sido cautos en el apoyo que brindaban a las práicticas populares, excepto cuando éstas se integraban a los templos oficiales, como es el caso de la Basilica de Guadalupe ${ }^{26}$. Sin embargo, un grupo de obispos que trabajaba en áreas rurales de México, especialmente en el Sudoeste, ha iniciado un interesante programa, el cual reconoce las tradiciones indígenas como base para la renovación de la comunidad ${ }^{27}$.

Este intento por incorporar la religión popular a formas más convencionales de práctica sacramental, ha sido estimulado por documentos del celam III (Puebla 1979). Estos documentos defienden la índole auténtica de la religio:idad popular, describiéndola como "el Catolicismo del Pueblo" (\$ 444). Los documentos de Puebla legitimizan el esfuerzo -cada vez más creciente en Latinoamérica- y que es especialmente significativo en el caso de la Iglesia Mexicana, de incorporar los rituales populares en las prácticas sacramentales y teológicas de la Iglesia y el comprender sus raf́ces sociales y políticas.

Tanto los documentos de Puebla como numerosas cartas pastorales de los obispos del Sudoeste (zona pastoral independiente con una coordinación y cooperación regional), han reconocido que los rituales populares representan valores religiosos genuinos y constituyen,

${ }^{25}$ Clodomiro Siller, "Evangelización y raíz religiosa popular", La evangelización en México (México: Ed. Paulinas, 1975), pp. 30-31. Por el mismo autor La réligiosidad popular en México (México: Sociedad Teológica Mexicana, 1975).

${ }^{20}$ Documentos colectivos del Episcopado Mexicano (México: Ed. Paulinas, 1977), Nos 2, 35.

27" "Fundamentos Teológicos de la Pastoral Indigena" (México: cenaMr, 1979). 
además, una protesta contra la explotación y trato deshumanizado a los pueblos indígenas ${ }^{28}$. La religión popular ha permitido a los líderes eclesiásticos establecer vínculos con los grupos rurales, lo que algunas veces ha creado conflictos con los intereses económicos y políticos locales. Estos conflictos también han surgido con las sectas protestantes que reciben financiamiento externo y que abogan por un discreto acercamiento a la religión y a la política.

\section{La conducción del cambio: un análisis}

La conducción del cambio en la Iglesia Mexicana se complica debido a diversos factores. Nuevos grupos de Iglesia están desarrollando formas de liderazgo laico y espiritualidad, apropiadas a sus miembros en su afán por relacionar sus vidas con la sociedad. La decreciente proporción clero-católicos, ha transformado el rol tradicional de los sacerdotes, como también el de los hombres y mujeres dentro de las órdenes religiosas e instituciones laicas. Las presiones del Vaticano y del CELAM sobre los obispos deben ser equilibradas mediante las relaciones directas con otras iglesias nacionales (de Latinoamérica, Estados Unidos, Canadá y Europa), quienes financian muchos de los programas realizados por los obispos. Los problemas de inmigración y pobreza han transformado a la familia, la unidad básica de la organización parroquial. A medida que los obispos enfrentan presiones sociales, ideológicas y organizacionales, las relaciones con el Estado deben ser públicamente manejadas. Las estructuras eclesiásticas, especialmente aquellas de liderazgo, no han evolucionado de manera de permitir la participación y responsabilidad laica que corresponde al desafio que se enfrenta. Algunos de estos desafíos serán analizados en el área de liderazgo, ministerio social y relaciones con el Estado.

\section{a. La crisis de autoridad y liderazgo}

La Iglesia Mexicana ha experimentado muchas crisis de la autoridad jerárquica desde los días de la Independencia. En el pasado, la intervención del Vaticano resolvía las crisis. Los actuales problemas de autoridad y liderazgo, en cambio, son más complicados que aquellos del pasado. En esos tiempos, los asuntos de liderazgo dentro de la Iglesia Mexicana eran materia exclusivamente clericales, manejadas por la jerarquía, confirmados o modificados por Roma. La unidad de la Iglesia estaba reforzada por una estructura de poder jerárquico y libre de amenazas externas de persecución, especialmente desde los tiempos de la Revolución. Hoy día, la repre-

${ }^{25}$ Documentos $\mathrm{y}$ comentarios finales de CELAM III pueden encontrarse en $\mathrm{J}$. Eagleson \& P. Scharper, Puebla y más allá (Maryknoll N. Y.: Orbis, 1979), Pp. $128-285$. 
sión politica es selectiva y no está dirigida contra la religión como tal. Los desacuerdos en relación al correcto ejercicio de la autoridad jerárquica y el liderazgo laico no pueden ser resueltos por Roma, ya que es la autoridad de Roma la que se encuentra en el centro de la controversia. Vaticano II ha pedido nuevas formas de organización eclesiástica y nuevas formas de liderazgo. Para los obispos mexicanos los cambios se ven muy obstaculizados por las presiones del pasado. Esta resistencia al cambio es especialmente notable en el Ârzobispo de Ciudad de México.

El Arzobispo de Ciudad de México es el prelado más poderoso de México, pero no puede controlar a la Iglesia como en el pasado. Los obispos tienen Conferencias Regionales las cuales son cada vez más influyentes. Las órdenes religiosas tienen su propia organización nacional y están integradas a un grupo regional mayor, vigente para toda Latinoamérica. En el pasado, el poder del Arzobispo de Giudad de México estaba respaldado por una amistad personal con el Presidente. Hoy en día tal relación ya no es aceptada incuestionablemente por los otros obispos y niembros laicos. Los teólogos, los líderes laicos y los obispos, están en abierto desacuerclo con los objetivos y procedimientos de las polf́ticas de la Iglesia ${ }^{29}$.

Los obispos de México e:tán internamente más divididos y polarizados que los obispos de jerarquías más numerosas, como son las de Brasil y los Estados Unidos. Mientras profundas diferencias teológicas y de organización caracterizan la mayoría de las iglesias nacionales en la actualidad, la Iglesia Mexicana ha sido particularmente lenta en desarrollar un mecanismo para resolver conflictos y diferencias. Los obispos se enfrentan unos a otros con un estilo e intensidad inusuales en otras iglesias. Esto, quizás, se debe al alto grado de personalización de poder en la Iglesia de México. Los conflictos están manejados por intervención personal de autoridades más altas, omitiendo a las organizaciones locales e intermedias, incluso para asuntos menores de poca envergadura. Esta dificultad en la conducción de los cambios es básicamente un problema estructural.

La crisis de autoridad en Ia Iglesia Mexicana está relacionada con las tensiones entre dos modelos de autoridad: la antigua jerarquía y el nuevo modelo participativo. El antiguo modelo se identifica con el tradicional acercamiento a la autoridad, centralizado a través de una cadena de mando que acepta las decisiones finales de la jerarquía y de las autoridades del Vaticano. El modelo participativo está muy lejos de encontrarse implantado en la Iglesia Mexicana, éste incluye la participación de los líderes laicos en la política

\footnotetext{
"Teresa Gurza, "Crisis de Autoridad en el Clero", Unomasuno, 12 de actubre de 198I, pp. 1, 5 .
} 
de la Iglesia, la cooperación con la Conferencia Nacional Episcopal y con las organizaciones sacerdotales (muchas de las cuales han sido ignoradas o disueltas por los obispos). Mientras los obispos mexicanos aceptan el modelo participativo en teoria, el poder y la autoridad continúan estando centralizados y personalizados con pocas estructuras para mediar conflictos y elaborar nuevos programas. A pesar de reafirmar la unidad de la Iglesia, y del intento del Vaticano para restringir la autonomía de los teólogos (asociados con la Teología de la Liberación) y órdenes religiosas, tanto la extrema derecha como la izquierda mexicana, han resistido eficazmente la autoridad de los obispos. Los obispos son desafiados por grupos que transforman sus creencias religiosas en cruzadas políticas las cuales cuestionan la universalidad de la doctrina de la Iglesia, y por otros grupos que excluyen las relaciones políticas y sociales -de cualquier tipo- con su religión. La controversia sobre la Teología de la Liberación tiene una especial significación para México. Para los líderes de la Conferencia Episcopal Mexicana (CEM), la Teología de la Liberación es más un problema de autoridad jerárquica que de ideología. Los teólogos de la liberación se han convertido en defensores de un sistema descentralizado de toma de decisiones dentro de la Iglesia, y del modelo participativo en la organización de la Iglesia.

\section{b. La Iglesia y la sociedad}

El ministerio social ha llegado a ser el mayor desafio y punto de controversia para los lideres de la Iglesia. El ministerio social compromete la relación de los valores religiosos en la sociedad. Hasta la década de los 60, la Acción Católica (AC) ha sido el mayor instrumento para canalizar la doctrina religiosa a la sociedad, siempre bajo el control de la jerarquía. La educación privada proporciona la mayor base de entrenamiento para miembros de la Acción Católica. Los dirigentes clericales permiten a la jerarquía presentar la doctrina social de la Iglesia como una alternativa al "colectivismo" $e$ individualismo. El anticomunismo proporcionaba una pantalla conveniente tanto para la disciplina interna de Ia Iglesia como para su compromiso con el Gobierno.

Desde Vaticano II, el ministerio social ha llegado a ser el núcleo de la renovación reljgiosa. Los líderes de la campaña anticomunista del pasado, se dieron cuenta de que se necesitaban cambios, tanto internamente como con respecto a las relaciones Iglesia-Estado y Sociedad-Iglesia. La Teología de la Liberación proporcionó un nuevo marco para relacionar espiritualidad, organización de la Iglesia y activismo soc:al. Otros grupos religiosos fuera del control jerárquico respondieron a las necesidades espirituales de sus miembros. La renovación carismática ha llegado a ser un movimiento 
importante de renovación religiosa para la clase media. Sin embargo, los obispos aún ven el protestantismo como un caballo de Troya para el liberalismo secular y a la Teología de la Liberación como una apertura para que el comunismo entre a la Iglesia: ambos amenazan destruir la vida cristiana y los valores nacionales.

El contexto de la controversia sobre la política social de la Iglesia ha tenido poco impacto en la masa de católicos. La brecha entre los líderes y miembros de la Iglesia es grande y problemática. La religión popular continúa siendo el soporte principal de la mayoría de los miembros de la Iglesia. Existen esporádicas campañas nacionales para renovar la religión concentrada en la Basílica de Guadalupe. Las cruzadas del rosario y procesiones a la Basílica de Guadalupe constituyen un intento débil para reconciliar a los progresistas que buscan un ministerio social más efectivo y a los conservadores que tratan de evitar las fórmulas políticas.

\section{c. Cambios en la relación Iglesia-Estado}

El Cardenal-Arzobispo de Ciudad de México ya no es más el único prelado involucrado en la política mexicana. Otros obispos indirectamente se están involucrando en materias políticas. Algunos obispos han prevenido a los católicos con respecto a la colaboración con partidos de izquierda, especialmente con el PSUM, un partido marxista que cuenta con fuerte apoyo católico. Varios obispos del Norte se han identificado con las políticas del partido opositor PAN. En las elecciones de junio de 1983, el PAN ganó los gobiernos municipales de capitales en cinco estados. Las autoridades locales ominosamente acusaron a los líderes de la Iglesia de involucrarse ilegalmente en los partidos políticos. Un influyente grupo regional de obispos se ha identificado con los pobres, permitiendo a los católicos votar por cualquier partido que trabaje por la justicia social, clave de la estrategia social de la Iglesia. Los observadores se preguntan cuán lejos podrán llegar los obispos sin causar una reacción desmedida del Estado.

El pasado aún domina la política mexicana. Puede ser un pasado revolucionario, pero no obstante es pasado. Es el pasado revolucionario que le da a la política su tinte peculiar y al Estado su legitimidad, produciendo especiales desafíos por parte de la Iglesia. Dentro de este marco, el retorno de la Iglesia a la política nacional crea problemas especiales. Los obispos han entrado tan repentinamente y masivamente a la arena pública que es inevitable una reacción. Aunque aparezca paradójico imponer restricciones legales en la religión mayoritaria del país, esto está determinado por políticas del pasado.

Un desafío al Estado para que remueva las molestas restricciones 
políticas y legales, puede tener implicancias impredecibles. Las políticas revolucionarias de este modo también están siendo desafiadas. En el pasado se cometieron enormes injusticias contra la Iglesia y sus miembros. Pero en esa época los líderes de la Iglesia formularon demandas desestabilizadoras e inaceptables por el Estado. Sin una renovación convincente y clara de la organización y procedimientos internos de la Iglesia, el apoyo a ésta podría dividirse y perder fuerza. Las relaciones Iglesia-Estado en la actualidad, a pesar de ser incómodas han permitido una de las renovaciones más amplias en la historia del catolicismo mexicano. Existen evidencias que sugieren que el llamado liderazgo moderado de los obispos desea una rcvisión de las relaciones Iglesia-Estado ya existentes. Esto significa que ellos buscan fortalecer su posición con el Estado para poder estabilizar presiones religiosas internas para la renovación. El problema con las nuevas demandas de la Iglesia es que para tener éxito ellas dependen de las alianzas políticas personalistas del pasado. Tales estrategias contradicen y minan el programa de renovación ondenado por Vaticano II. El futuro de la Iglesia Mexicana nuevamente depende de su propia habilidad para definirse y defenderse contra un Estado que persigue controlar a la Iglesia y utilizarla para sus propios fines. 